\title{
Decreased glomerular filtration with age, a normal phenomenon
}

\section{Disminución del filtrado glomerular con la edad, un fenómeno normal}

Diego H. Ramírez-Leyva*

Instituto Mexicano del Seguro Social, Family Medicine Unit 1, Sonora, Mexico

I read with interest "Occult renal failure and associated factors in patients with chronic conditions", by Balderas Vargas et al., ${ }^{1}$ published in issue 1 of 2020 Gaceta Médica de México. In the article, the authors mention age as a risk factor for occult renal failure, a result that should be taken with caution since renal aging elicits that result without the presence of injury.

It is important to explain why the authors suggest 60 years of age as a cutoff point to consider age as a risk factor, since it is normal for individuals to have decreased kidney function ( $0.8 \mathrm{~mL} /$ hour per year) since 40 years of age or even before. ${ }^{2}$ The explanation of this significant factor is not mentioned in the discussion section of the article. In my opinion, it does not apply as a risk factor and only corresponds to the normal process of aging. It seems to me more appropriate measuring the expected renal function according to the age and, subsequently, assessing for the presence of occult renal failure. ${ }^{3,4}$

The article also mentions the control of diabetes mellitus and high blood pressure as an associated factor, but it does not indicate how it was determined, which affects the results, since the control of chronic diseases is precisely a determining factor for renal function. ${ }^{5}$ In this aspect, measurement of glucose, glycated hemoglobin and blood pressure in their natural form would allow a better appreciation than the control-lack of control dichotomy. In this sense, evolution time is not mentioned in the results or in the discussion. From my perspective, that variable would modify the results.

\section{References}

1. Balderas-Vargas NA, Legorreta-Soberanis J, Paredes-Solís S, Flores-Moreno M, Serrano-de los Santos FR, Andersson N. Insuficiencia renal oculta y factores asociados en pacientes con enfermedades crónicas. Gac Med Mex. 2020:156:11-16.

2. Davies DF, Shock NW. Age changes in glomerular filtration rate, effective renal plasma flow, and tubular excretory capacity in adult males. $J$ Clin Invest. 1950;29:496-507.

3. Otero-González A. Envejecimiento y función renal. Mecanismos de predicción y progresión. Nefrol Sup Ext. 2011;2:119-130.

4. Muntner P. Longitudinal measurements of renal function. Semin Nephrol. 2009:29:650-657.

5. Maclsaac RJ, Jerums G, Ekinci El. Effects of glycaemic management on diabetic kidney disease. World J Diabetes. 2017;8:172-186.
Gac Med Mex. 2020;156:353

Contents available at PubMed www.gacetamedicademexico.com 0016-3813/@ 2020 Academia Nacional de Medicina de México, A.C.. Published by Permanyer. This is an open access article under the CC BY-NC-ND license (http://creativecommons.org/licenses/by-nc-nd/4.0/). 